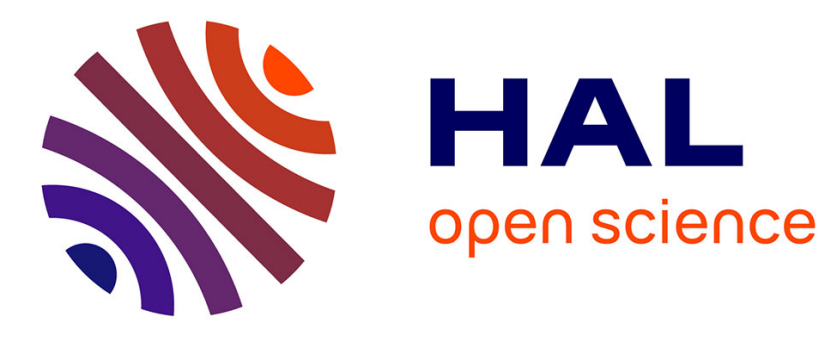

\title{
On-Chip Temperature Monitoring of a SiC Current Limiter
}

\author{
Dominique Tournier, Phillippe Godignon, José Millan, Dominique Planson, \\ Jean-Pierre Chante, F. Sarrus, J.-F. de Palma
}

\section{- To cite this version:}

Dominique Tournier, Phillippe Godignon, José Millan, Dominique Planson, Jean-Pierre Chante, et al.. On-Chip Temperature Monitoring of a SiC Current Limiter. Materials Science Forum, 2004, 457-460, pp.1021-1024. 10.4028/www.scientific.net/MSF.457-460.1021 . hal-02966528

\section{HAL Id: hal-02966528 \\ https://hal.science/hal-02966528}

Submitted on 14 Oct 2020

HAL is a multi-disciplinary open access archive for the deposit and dissemination of scientific research documents, whether they are published or not. The documents may come from teaching and research institutions in France or abroad, or from public or private research centers.
L'archive ouverte pluridisciplinaire HAL, est destinée au dépôt et à la diffusion de documents scientifiques de niveau recherche, publiés ou non, émanant des établissements d'enseignement et de recherche français ou étrangers, des laboratoires publics ou privés. 


\title{
On-Chip Temperature Monitoring of a SiC Current Limiter
}

\author{
Dominique Tournier ${ }^{1}$, Philippe Godignon ${ }^{1}$, José Millan ${ }^{1}$, Dominique Planson², \\ Jean Pierre Chante ${ }^{2}$, Franck Sarrus ${ }^{3}$, Jean François de Palma ${ }^{3}$ \\ ${ }^{1}$ Centro Nacional de Microelectronica (CNM), Campus Universidad Autónoma de Barcelona, \\ 08193 Bellaterra, España \\ ${ }^{2}$ Centre de Génie Electrique de Lyon (CEGELY) INSA-LYON, UMR 5005 CNRS, Bât. L. de Vinci, \\ 21 Av. Capelle Ouest, 69621 Villeurbanne, France \\ ${ }^{3}$ Ferraz Shawmut, rue Vaucanson, 69720 St Bonnet de Mure, France
}

Keywords: Current limiter, temperature sensor, reliability, packaging.

\begin{abstract}
High voltage and high current potentiality of $\mathrm{SiC}$ based devices has been proved, and various devices able to work at high temperature have been reported as well. Nevertheless, packaging is one of the main constrains for high temperature operation of these devices. Up to date, no specific power package has been reported for high temperature operation. Moreover, it is desirable to predict the $\mathrm{SiC}$ die temperature to avoid any related failure in order to improve the efficiency of the packaged $\mathrm{SiC}$ device.

This paper deals with an integrated temperature sensor for SiC current limiting devices. The current limiter is based on a VJFET structure, which capability for dissipating high power density (140 $\mathrm{kW} / \mathrm{cm}^{2}$ ), in the limiting state, has been previously demonstrated [2]. Carrier mobility dependence with temperature was extracted from cryogenic measurements. The temperature estimation is based on the measurement of the variation of the electrical resistance (caused by mobility variation) of the sensing device integrated with the current limiter.

In this paper we will first describe the temperature estimation methodology using various technological solution (from metallic resistor solution to the $\mathrm{SiC}$ integrated sensor). Then experimental temperature measurements using an integrated $\mathrm{SiC}$ sensor within a packaged current limiting devices will be presented. Electro-thermal measurements on the fabricated devices show that the current limiter is able to work at $205^{\circ} \mathrm{C}$ under steady state conditions $(320 \mathrm{~V})$, without degrading their electrical performances. Finally, perspectives in terms of integration and reliability will be proposed.
\end{abstract}

\section{Introduction}

In order to get the full benefit of silicon carbide material properties; i. e. high voltage and high temperature working operation [1], the development of specific package is a great challenge on the roadmap to silicon carbide technology. Therefore a great effort has to be put on packaging development and reliability study. In this field and in order to monitor devices temperature, we have implemented a very simple integrated temperature sensor.

It is critical to reduce thermal interfaces between heating and sensing elements in order to reach a certain precision on temperature rising during transient operation. Conventional metallic sensor can be used (Pt, or Al made). Nevertheless, the drawback of such devices lies on their thermal response time. Moreover their thermal sensibility and the different thermal expansion coefficients in comparison to $\mathrm{SiC}$ leads to mechanical stress and finally makes the sensor subject to failure or derating.

In the case of a metal layer, the variation of the resistivity of the metal can be assumed to vary lineally with temperature, that makes simple the temperature rising estimation. However, we have preferred the integrated $\mathrm{SiC}$ sensor option to get a more reliable temperature monitoring. 


\section{Sensor and methodology description}

\section{Temperature sensor description}

Unlike metallic sensor, an integrated sensor has the advantage to reduce interface layers effect and mechanical stress since the sensor is integrated with the device (figure 2). The sensor consists in a resistor that can be vertically or laterally integrated within the current limiting device. The lateral sensor has the advantage of being fully insulated by the Pburied layer.

In addition, the response time of the sensing element will be almost the same to that of the heating element.

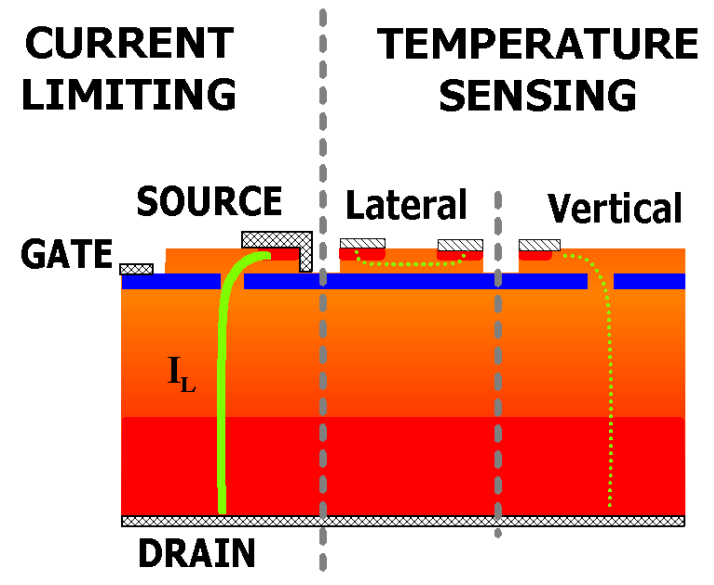

Fig. 2.- Cross-section of the integrated temperature sensor with the current limiter.

We have used a LVJFET current limiter with a high power density $\left(140 \mathrm{~kW} / \mathrm{cm}^{2}\right)$, which has been previously checked [2], to demonstrate the possibility to measure the temperature evolution. The mobility variation with temperature is assumed to vary as describe in (1).

$$
\mu(\theta)=f\left(\left(\frac{\theta}{\theta_{0}}\right)^{\alpha}\right) \text {. Equation } 1 .
$$

The dependence coefficient " $\alpha$ " was extracted through cryogenic measurements $(\alpha=2.2$ was found, close to literature reported results [3]).The temperature estimation technique, based on this law, will be analysed below and then illustrated by experimental measurements on a packaged current limiting device.

\section{Temperature estimation methodology}

The temperature estimation is based on the measurement of the resistance variation (caused by mobility variation) of the sensing device. Fig. 2 shows the integrated temperature sensor with the current limiter. The measured sensor resistance is inversely proportional to mobility. Measurements of the resistance variation, $\Delta \mathrm{R}$, with temperature $\Delta \theta$ allow to simply compute the temperature, $\theta$, if one knows a reference resistance value at room temperature $\left(\mathrm{R}_{0}, \theta_{\mathrm{amb}}\right)$ :

$$
\Delta R(\theta)=\beta \times \frac{\rho \times L}{S}=\beta \times \frac{L}{S} \times \frac{1}{N \times q \times \mu(\theta)}=K \times\left(\frac{1}{\mu(\theta)}\right)=R_{0} \times\left[\left(\frac{\theta}{\theta_{0}}\right)^{\alpha}\right] . \text { Equation } 2 .
$$

( $\mathrm{K}$ includes sensor parameters: channel section and width). From (2), we can deduce the relation between $\theta$ and $\mathrm{R}_{\theta}$ :

$$
\theta=\theta_{0} \times\left(\frac{R_{0}-R_{\theta}}{R_{0}}\right)^{1 / \alpha} \text {. Equation } 3
$$




\section{Experimental results}

\section{Method validation: IR measurements}

According to Mc Cluskey [4], plastics packaged devices are able to work at temperature around $125^{\circ} \mathrm{C}$ with the same reliability as ceramic or metallic package. Thermal ageing study shows that a stable behaviour is achieved at temperatures as high as $175^{\circ} \mathrm{C}$. Thus, we have assumed a maximal case temperature of $150^{\circ} \mathrm{C}$ to perform our study. Back case temperature was measured with a K-type thermocouple. Measurements were done using a cellular current limiter as heater and a vertical VJFET as sensor. The die $(4 \mathrm{~mm} \times 4 \mathrm{~mm})$ was soldered in a TO220 metallic package (figure 3 ).

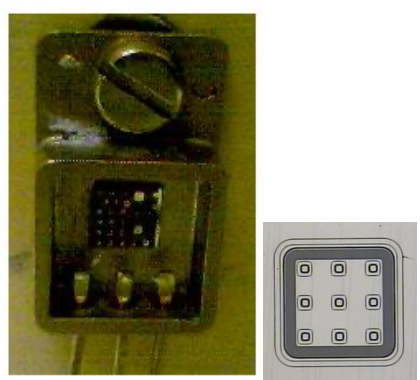

Fig. 3.- Packaged current limiter (metallic TO-220 package).

(die de $4 \mathrm{~mm} \times 4 \mathrm{~mm}$ )

(limiter $460 \mu \mathrm{m} \times 460 \mu \mathrm{m}$ )

IR-measurements were performed to check the temperature distribution between the heating device $(\mathrm{H})$ and the sensing device $(\mathrm{S})$. The figure 5 shows two cross sections along line L01 of figure 4 for two different $\mathrm{V}_{\mathrm{DS}}$ bias applied to the current limiter $\left(\mathrm{V}_{\mathrm{DS}}=21 \mathrm{~V}\right.$ and $\left.\mathrm{V}_{\mathrm{DS}}=42 \mathrm{~V}\right)$. We can see from figure 5 that the contact metal temperature is similar in both the heating element $(\mathrm{H}$, at $0.4 \mathrm{~mm})$ and sensing element $\left(\mathrm{S}\right.$, at $1.2 \mathrm{~mm}$ ) for both $\mathrm{V}_{\mathrm{DS}}$ applied bias.

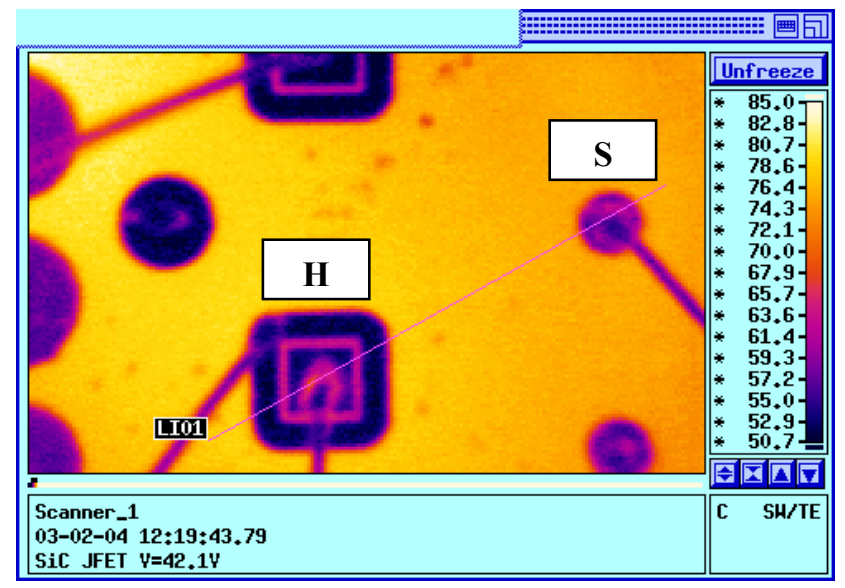

Fig. 4.- IR measurement at low drain bias $\left(V_{D S}=42 \mathrm{~V}\right)$ on heating $(\mathrm{H})$ and sensing $(\mathrm{S})$ chips

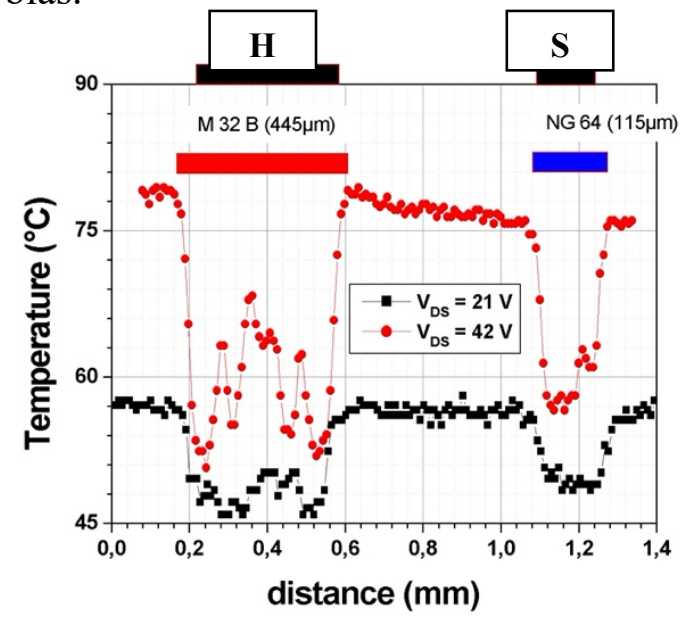

Fig. 5.- Temperature cross-section along LI01 of the left IR-picture (fig. 4).

The IR measurements confirm the fact that the temperature is similar in both devices and corroborates the temperature measurement feasibility.

\section{Temperature measurements}

Once experimentally confirmed the homogenous distribution of temperature, electro-thermal measurements were carried out. Resistance measurements were done using two Keithley controlled sources. Different set-ups C1, C2 and C3 were used to get various dissipated power values. No heat sink was used for set-ups $\mathrm{C} 1$ and $\mathrm{C} 2$, while a cooling element was used in set-up C3. Another difference consists in the gate electrode polarization that was either leaved floating or connected to the source electrode to achieve different output current levels. For each set-up, a maximum case temperature $\mathrm{T}_{\max }=150^{\circ} \mathrm{C}$ was fixed. The measurement was stopped when $\mathrm{T}_{\max }$ was reached. $\mathrm{I}_{\mathrm{DS}}\left(\mathrm{V}_{\mathrm{DS}}\right)$ curves where measured in steady state and the SiC temperature computed form the sensor. Current and temperature measurements are presented in figure 6 . 


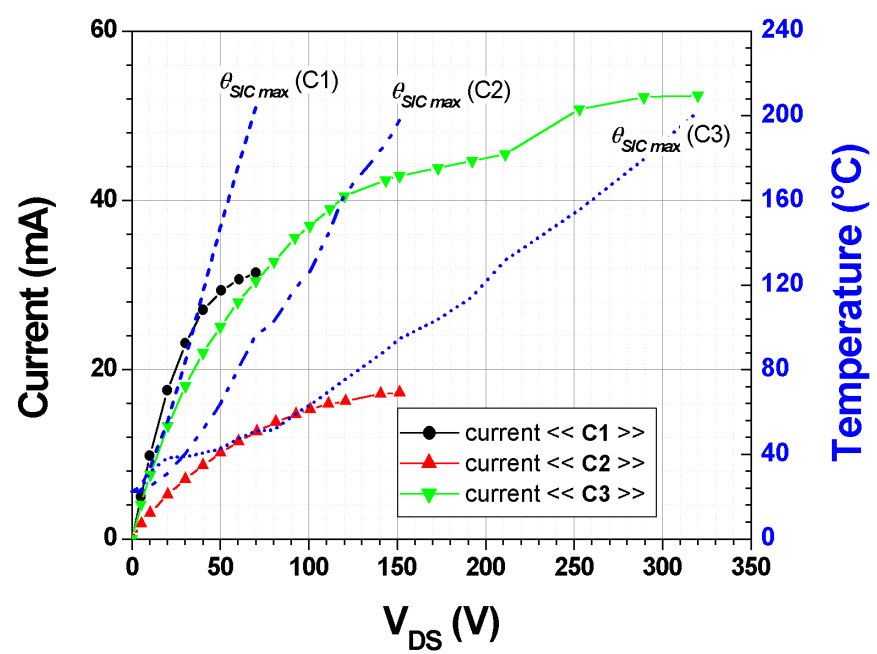

For set-up $\mathrm{C} 3$, a maximum $\mathrm{SiC}$ temperature of $201{ }^{\circ} \mathrm{C}$ is reached at a very high source power density $(825$ $\mathrm{kW} / \mathrm{cm}^{2}$ ). These results show that the current limiter is able to work at $201^{\circ} \mathrm{C}$ under steady state conditions $(320 \mathrm{~V})$, without degrading neither the electrical performances nor the current limiting function. Results summarized in table 2 shows that high current density can be achieved as well as the temperature monitoring.

Fig. 6.- Experimental I(V) curves and temperature estimation for the set-ups indicated in table 2.

Table. 2. Measurements and estimated temperature for the various experiments $(\mathrm{C1}, \mathrm{C} 2, \mathrm{C} 3)$

\begin{tabular}{|c|c|c|c|c|}
\hline \multicolumn{2}{|c|}{ Experiment } & C1 (V GS floating) & $\mathrm{C2}\left(\mathrm{V}_{\mathrm{GS}}=0 \mathrm{~V}\right)$ & C3 (V VS $_{\text {GS }}$ floating) \\
\hline \multicolumn{2}{|c|}{ COOLING } & NO & $\begin{array}{c}\text { NO } \\
\end{array}$ & YES \\
\hline \multicolumn{2}{|c|}{$V_{D S} \max (V)$} & $70 \mathrm{~V}$ & $151 \mathrm{~V}$ & $320 \mathrm{~V}$ \\
\hline \multicolumn{2}{|c|}{ IDs max (mA) } & $31.4 \mathrm{~mA}$ & $17.3 \mathrm{~mA}$ & $52.4 \mathrm{~mA}$ \\
\hline \multirow{2}{*}{$\mathbf{J}_{\mathbf{M A X}\left(\mathbf{A} / \mathbf{c m}^{2}\right)}$} & Total Area & $38 \mathrm{~A} / \mathrm{cm}^{2}$ & $21 \mathrm{~A} / \mathrm{cm}^{2}$ & $63 \mathrm{~A} / \mathrm{cm}^{2}$ \\
\hline & Source Area & $1558 \mathrm{~A} / \mathrm{cm}^{2}$ & $858 \mathrm{~A} / \mathrm{cm}^{2}$ & $2580 \mathrm{~A} / \mathrm{cm}^{2}$ \\
\hline \multicolumn{2}{|c|}{$P \max (W)$} & $2.2 \mathrm{~W}$ & $2.6 \mathrm{~W}$ & $16.8 \mathrm{~W}$ \\
\hline \multicolumn{2}{|c|}{$\mathbf{T}_{\text {SiC Max }}\left({ }^{\circ} \mathrm{C}\right)$} & $204^{\circ} \mathrm{C}$ & $215^{\circ} \mathrm{C}$ & $201^{\circ} \mathrm{C}$ \\
\hline \multicolumn{2}{|c|}{ TPackage MAX } & $156^{\circ} \mathrm{C}$ & $156^{\circ} \mathrm{C}$ & $151^{\circ} \mathrm{C}$ \\
\hline
\end{tabular}

Thus, we have been able to measure the temperature in limiting operation, which is an important issue when dealing with current limiting devices since temperature is a feed-back parameter for power losses control. Furthermore, the use of an appropriate gate drive will permit to reduce power losses and temperature rising and, consequently to reduce the cooling system size.

\section{Conclusion}

We have proposed and illustrate a very simple way to perform on chip temperature monitoring of $\mathrm{SiC}$ current limiter with an integrated sensor. Electro-thermal measurements on the fabricated devices have shown that the current limiter is able to work at $205^{\circ} \mathrm{C}$, under steady state conditions $(320 \mathrm{~V})$, without degrading their electrical characteristics. Different cooling set-ups have been used to illustrate both the temperature measurement and the high current density working operation of $\mathrm{SiC}$ devices. Next challenge will consist in the design of a fully integrated current limiter including temperature sensor to be able to prevent any thermal runaway of the packaged device. Such a device will be based on a combination of LVJFET, MESFET and a SiC thermal sensor.

\section{References}

[1] H. Matsunami, "Progess in Wide Bandgap Semiconductor SiC for Power Devices", $12^{\text {th }}$ International Symposium on Power Semiconductor Devices \& ICs", IEEE, Piscataway, NJ, USA, 2000, pp. 3-9.

[2] D. Tournier, Ph. Godignon, J. Montserrat, D. Planson, C. Raynaud, J.P. Chante, F. Sarrus, C. Bonhomme, J.F. de Palma, "A 4H-SiC High power density VJFET as Controlled current limiter", $37^{\text {th }}$ IAS Annual Meeting, 2002, vol. 3, pp. 2248-51.

[3] M. Ruff, H. Mitlehner, R. Helbig, « SiC devices: Physics and Numerical Simulation», IEEE Trans. Electron Devices ED-41 n6 June 1994.

[4] P. McCluskey, K. Mensah, C. O’Connor, A. Gallo, "Reliable use of commercial technology in high temperature environments”, Microelectronics Reliability, 2000, vol. 40, pp. 1671-78. 